\title{
ENSINO-APRENDIZAGEM - QUANDO O ALUNO SE TORNA TUTOR DO CONHECIMENTO ADQUIRIDO: UMA REVISÃO DE LITERATURA
}

\author{
TEACHING - WHEN A STUDENT BECOMES A TUTOR OF ACQUIRED \\ KNOWLEDGE: A LITERATURE REVIEW
}

\section{RESUMO}

Maiane Dequigiovanni ${ }^{1}$

Este estudo investigou sobre o método de ensino-aprendizagem que estimula e direciona o aluno para que ele se torne o tutor do próprio conhecimento, pois a concepção da educação humana mudou com o passar do tempo, adotando novos conceitos e teorias. Objetivos: O objetivo primário foi revisar o conteúdo que envolve a temática pesquisada, refletindo sobre a revolução do saber educativo, que terminou com o retrocesso da pedagogia, mediante as necessidades de sociedades cada vez mais dinâmicas, que requerem dos sujeitos a contribuição e assimilação de valores. Os objetivos secundários se resumem em: aplicar o método de revisão narrativa; analisar as informações; e apresentar os resultados, após uma discussão com os autores. Método: A metodologia empregada é de revisão narrativa de literatura, método de pesquisa que não utiliza critérios explícitos e sistemáticos, nem buscas sofisticadas e exaustivas para não esgotar as fontes de informações. Resultados: A literatura analisada contraindicou a implementação de padronizações ou generalização de condutas "não metodológicas" ao educando, recomendando novos estudos direcionados ao planejamento e produção de metodologias inovadoras, que possam formar sujeitos sociais e contributivos. Conclusão: A Aprendizagem Baseada em Problemas (ABP) mostrou-se a mais eficiente na apropriação e gestão do conhecimento, considerando que a escola é o "lugar" específico de cumplicidade e conspiração entre seus protagonistas na prática desse processo.

Palavras-chave: Ensino-aprendizagem; Conhecimento; Aluno-Tutor do Saber.

\section{ABSTRACT}

This study investigated the teaching-learning method that stimulates and directs the student to become the tutor of their own knowledge, because the conception of human education has changed over time, adopting new concepts and theories. Objectives: The primary objective was to review the content that involves the research theme, reflecting on the revolution of educational knowledge, which ended with the retrogression of pedagogy, through the needs of increasingly dynamic societies, which require the contribution and assimilation of subjects. values. The secondary objectives are summarized in: apply the narrative review method; analyze the information; and present the results after a discussion with the authors. Method: The methodology used is a narrative literature review, a research method that does not use explicit and systematic criteria, nor sophisticated and exhaustive searches not to exhaust the sources of information. Results: The literature analyzed contraindicated the implementation of standardization or generalization of "non-methodological" behaviors to the student, recommending new studies directed to the planning and production of innovative methodologies that can form social and contributive subjects. Conclusion: Problem-Based Learning (PBL) proved to be the most efficient in the appropriation and management of knowledge, considering that the school is the specific "place" of complicity and conspiracy among its protagonists in the practice of this process.

1 Professora e Empresaria; Administração; UNIT- Centro Universitário do Triangulo. Uberlândia-MG; Mestranda em Ciência da Educação; IESVA-Instituto de Ensino Superior Vanguarda. Araguaína - TO. 
Keywords: Teaching and learning; Knowledge; Student-Tutor of Knowledge. INTRODUÇÃO

O ensino-aprendizagem se desenvolveu nas últimas décadas, transformando os métodos ativos em metodologias de ensino não apenas para a transmissão do já conhecido, mas no processo que leva à capacidade de observação e de reflexão crítica, possibilitando ao aluno ser tutor do conhecimento adquirido em sala de aula (texto da Autora).

A verdade é que a concepção da educação humana mudou com o passar do tempo, porém alguns métodos utilizados cotidianamente, como os de forma polissêmica, passaram a comprometer a formação dos indivíduos: “[...] sem que se questione sua origem, seus significados e suas possíveis apropriações ideológicas” (RAMOS, 2014, p. 84).

A transformação da pedagogia ocorreu a partir da segunda metade do século XX, se impondo no âmbito mundial na redefinição de sua identidade: "[...] renovando seus limites e deslocado o seu eixo epistemológico [...]", quando "[...] passou a ser uma Ciência da Educação, de um saber único e fechado para um saber aberto e amplo" (Cambi, 1999 apud CAMILLO; MEDEIROS, 2018, p. 28).

Segundo Ramos (2014), há dois pressupostos importantes à formação humana, que sugerem uma superação da divisão histórica do ser humano, em função da divisão social do trabalho entre as ações de executar, dirigir e planejar, que são:

O primeiro deles é a compreensão dos seres humanos como históricos e sociais. O
segundo enfatiza que a realidade concreta é uma totalidade, síntese de múltiplas
relações. Portanto, para ser compreendida e transformada, deve ser apreendida em
suas mediações (RAMOS, 2014, p. 84).

Prossegue Ramos (2014, p. 86): “[...] por isto, o trabalho é a mediação ontológica e histórica na produção do conhecimento". Sendo que as dimensões da "vida" do aluno no processo educativo são constituídas pelo trabalho, a ciência e a cultura, onde essa última compreende os valores que orientam as normas de conduta de uma sociedade, lugar em que o sujeito deverá pôr em prática a gerência do próprio conhecimento. Entretanto, os estudantes não terão a devida compreensão sobre o significado das teorias e conceitos produzidos em sala de aula se esses não se vincularem a problemas concretos do cotidiano.

No atual contexto da globalização, o conhecimento passou a ser: "[...] o principal fator de diferenciação competitiva" (DAVILA; et al, 2015, p. 45), que pode ser explícito, quando é transmitido em linguagem formal e sistemática; ou tácito, quando é de apropriação do sujeito e se constitui em vantagem competitiva pessoal e/ou organizacional. Assim, a gestão do conhecimento (GC) é um processo dinâmico, orientado por meio de "ciclos" que passam pelas fases: capturar, apropriar, criar, gerar, compartilhar (quando ele é disseminado), e 
aplicar (utilizar) com o objetivo de "agregar e gerar" valor para si e para o meio (DAVILA; et al, 2015).

Em meados do século XX, o norte-americano Carl Rogers desenvolveu a Teoria Rogeriana, que define que sanidade mental se constitui em: “[...] desenvolvimento pleno das potencialidades pessoais, são tendências naturais da evolução humana. Removidos eventuais obstáculos nesse processo, as pessoas retomam à progressão construtiva" (FERRARI, 2008, p. 2). Rogers conceituou o educador como um "terapeuta" do aluno, facilitador do aprendizado, onde o estudante se torna "o paciente", para que possa se transformar no final do processo de apropriação em "tutor" do conhecimento por ele adquirido.

De acordo com Gonzalez e Martins (2017), o conhecimento é desenvolvido através de um ciclo evolutivo, dentro do processo de ensino-aprendizagem, iniciando com a observação e organização das informações, a partir de dados estruturados, até atingir a sua plena apropriação. No entanto, nem todos os alunos alcançam o nível de "tutor" do saber adquirido em sala de aula, que é o ganho de sabedoria por parte do indivíduo, que pode ser disseminada em um grupo, mas que só se desenvolve conforme cresce a experiência pessoal de cada ser humano (GONZALEZ; MARTINS, 2017).

O processo de ensino-aprendizagem é um complexo sistema de interações comportamentais entre o professor e o aluno, e se constitui, respectivamente, nos fenômenos de "educar" e "aprender", onde a produção do resultado ocorrerá a partir da implementação dos aspectos concretos da realidade (situação) em sala de aula, com os quais o sujeito defrontar-se-á no cotidiano ou precisará lidar (KUBO; BOTOMÉ, 2005).

Neste contexto, a Aprendizagem Baseada em Problemas (ABP) surgiu como um método inovador e estratégico, com o objetivo de solucionar ou simular um problema real, a partir de um contexto centrado no aluno: “[...] que deixa o papel de receptor passivo do conhecimento e assume o lugar de protagonista do próprio aprendizado [...]” (SOUZA; DOURADO, 2015, p. 182).

A temática aqui desenvolvida tem relevância social por se tratar de um estudo que envolve as competências, habilidades e atitudes que o educador necessita ter para que o aluno, ao final do curso da disciplina, se transforme no tutor do seu próprio conhecimento e possa gerenciá-lo no seu cotidiano (CAMILLO; MEDEIROS, 2018).

Frente às considerações citadas, tornou-se importante e pertinente realizar esta revisão narrativa de literatura, com a finalidade de esclarecer a seguinte questão norteadora: Como deve ser o "proceder" do educador no processo de ensino-aprendizagem para que o aluno se torne tutor do próprio conhecimento? Para responder essa pergunta tivemos como base de 
estudos o conteúdo das obras bibliográficas aqui referenciadas, a partir do qual se pôde chegar à conclusão final da pesquisa. Foi uma forma de se trazer as evidências, perspectivas, aplicabilidade e resultados dos métodos ativos de ensino à luz, de maneira analítica.

Este estudo tem como objetivo primário revisar o conteúdo que envolve a temática pesquisada, refletindo sobre a revolução do saber educativo, que colocou um ponto final no retrocesso da pedagogia, diante das necessidades de sociedades cada vez mais dinâmicas, que requerem dos sujeitos a contribuição e assimilação de valores. Os objetivos secundários se resumem em: aplicar o método bibliográfico de revisão narrativa de literatura; analisar o conteúdo das obras referenciadas; apresentar os resultados e, em seguida, propor uma discussão com os autores referenciados, de forma que se possa chegar, mais facilmente, à conclusão dos dados.

A presente pesquisa se encontra organizada em capítulos, aqui apresentados em forma de "títulos", iniciando com a apresentação da metodologia de construção do conteúdo; identificação e conceituação dos elementos pertinentes ao tema; seguidas da análise das informações; apresentação dos resultados; e conclusão do assunto.

A justificativa pelo desenvolvimento deste estudo, além da relevância do tema e seus descritores, foi pelo interesse da Autora-Pesquisadora em adquirir este conhecimento para aplicação em futuras ações profissionais.

\section{MÉTODO}

A metodologia empregada neste estudo é de revisão narrativa de literatura, método de pesquisa que não utiliza critérios explícitos e sistemáticos para a busca e análise crítica dos dados, para não esgotar as fontes de informações. Portanto, na revisão narrativa não se aplica estratégias de busca sofisticadas e exaustivas na seleção dos estudos, para que a interpretação dos dados permaneça sujeita à subjetividade dos autores.

Assim, a revisão narrativa de literatura vem se constituir como o método adequado na fundamentação teórica de um artigo científico, onde se faz necessário um estudo profundo da prática educativa baseada em evidências, o que também facilita a incorporação de um vasto leque de propósitos: definição de conceitos; revisão de teorias e informações; e análise de problemas metodológicos referentes ao ensino-aprendizagem, de maneira que possibilite ao aluno adquirir condições de realizar a gestão do próprio "saber" adquirido em sala de aula.

$\mathrm{Na}$ construção do conteúdo foram utilizadas todas as etapas previstas em um "protocolo de revisão narrativa de literatura": identificação do tema e elaboração da pergunta norteadora; busca da literatura a partir de critérios de inclusão e exclusão definidos; definição 
das informações a serem extraídas dos estudos selecionados, por meio de uma ficha bibliográfica previamente construída; coleta de dados; avaliação com análise das informações; apresentação dos resultados; discussão dos dados; e conclusão final.

A abordagem deste estudo é qualitativa, se delimitando da seguinte forma: $1^{\mathrm{a}}$ ) Delimitação geográfica: à educação no âmbito nacional; $2^{\mathrm{a}}$ ) Delimitação por categoria profissional: aos professores no âmbito nacional, preferencialmente àqueles que trabalham em escolas públicas; $3^{\mathrm{a}}$ ) Delimitação por grupo de estudos: à população de estudantes brasileiros, especialmente alunos do Ensino Médio; e $4^{a}$ ) Delimitação por indicadores: cumplicidade e conspiração na apropriação/gestão do conhecimento.

A temática pesquisada se limitou à busca pelos seguintes assuntos: Teoria e Métodos de Ensino-Aprendizagem; Métodos Ativos de Ensino; Ciclos da Gestão do Conhecimento; Teoria Rogeriana; A interação entre os Processos Comportamental e de Gestão do Conhecimento; Atividades de Ensino-aprendizagem; Limites e possibilidades de apropriação do conhecimento em sala de aula; Apropriação do conhecimento em escolas públicas; Aprendizagem Baseada em Problemas (ABP); e o Papel do Professor como facilitar do aprendizado.

Os objetivos propostos foram realizados a partir de um levantamento bibliográfico retrospectivo de 1992 a 2019, obtido em acervos bibliográficos, físicos e digitais, em plataformas da web, banco de dados da Biblioteca Virtual em Educação (BVE), informativos de Portais, e materiais didático-científicos necessários ao estudo, utilizando os descritores: Ensino-aprendizagem; Conhecimento; Aluno-Tutor do Saber.

A definição das datas do período pesquisado se justifica pela necessidade de uma ampla investigação sobre o assunto, onde uma análise mais detalhada dessas publicações ainda não havia sido realizada. Por outro lado, uma investigação sobre o panorama do EnsinoAprendizagem no Brasil, desde última década do século XX é algo que poderá, no futuro, contribuir para a avaliação e acompanhamento deste campo de pesquisa.

A escolha da BVE e da web se deve ao fato de se configurarem em um dos mais abrangentes índices da literatura científico-educacional da atualidade, pois contemplam indispensável banco de dados como o de literatura nacional e internacional, publicados em Revistas (Do Inst. J. Knowl Manage; Gestão da Produção; UFSC; Perspectiva; Perspectiva em Gestão \& Conhecimento; e Holos); Informativo do Poder Público (Nova Escola); e Dados de Portais (Dia-a-Dia Educação), todos disponíveis on-line, exceto o Material Didático-científico de Editoras (FURG; IFPR; e NTE), dentre outros necessários ao estudo. 
Para realizar a revisão narrativa de literatura foram utilizados critérios seletivos de inclusão e exclusão de conteúdos, aplicados no total de "26" (100\%) obras científicas selecionadas, dentre as quais apenas " 12 " $(46,15 \%)$ abordaram os descritores em toda a sua extensão, onde os artigos se constituíram nos principais meios de divulgação dos trabalhos relacionados à temática pesquisada no período de 1992 a 2019. Os anos com maior incidência de publicações foram 2008 e 2015, enquanto que nos anos de 1993-2004, 2006, 2007, 20092011, e 2016 não houve nenhuma publicação sobre o assunto, apesar de se encontrarem incluídos no período de estudos. A “Tabela 1" apresenta a relação de conteúdos quanto aos percentuais de publicação por ano, anos sem publicações, e os anos com maior incidência.

Tabela 1: Percentuais e número de obras relacionadas por incidência ou ausência de publicação/ano.

\begin{tabular}{|c|c|c|c|}
\hline $\begin{array}{l}\text { \% de Obras por ano de Publicação } \\
\text { em relação à “26” Obras: }\end{array}$ & Anos com Publicações: & Anos sem Publicações: & $\begin{array}{c}\text { Ano com maior } \\
\text { incidência de } \\
\text { Publicações: }\end{array}$ \\
\hline $100 \%$ & 26 & - & - \\
\hline 46,15 & 12 & - & - \\
\hline 7,69 & - & - & 2 \\
\hline 65,38 & - & 17 & - \\
\hline
\end{tabular}

Fonte: Própria Autora (2019).

O conteúdo selecionado $(n=26 ; 100 \%)$ foi submetido ao processo de exclusão de obras, onde se adotou a eliminação por etapas através de filtros: $1^{\mathrm{a}}$ ) $\mathrm{O}$ primeiro filtro foi de exclusão de obras publicadas em data anterior ao ano de 1992, onde restaram "20" conteúdos; $2^{\text {a }) ~ F o i ~ a p l i c a d o ~ o ~ s e g u n d o ~ e ~ u ́ l t i m o ~ f i l t r o, ~ d e ~ " d u p l i c i d a d e ~ d e ~ a b o r d a g e m ”, ~ o n d e ~ r e s t a r a m ~}$ "12" obras científicas de literatura nacional, selecionadas para leitura e fichamento prévio e, em seguida, para a construção da lista de referências bibliográficas. A "Tabela 2" ilustra o processo de eliminação por "filtros", apresentando o percentual destes no total de "26" conteúdos.

Tabela 2: Processo de Exclusão com Eliminação por Filtros.

\begin{tabular}{|c|c|c|}
\hline \multicolumn{2}{|c|}{ Processo de Eliminação por Filtros em Etapas } \\
\hline Etapas: & Filtros: & $\begin{array}{c}\mathbf{N}^{\mathbf{0}} \text { de Conteúdos Excluídos no total de } \\
\text { '26' Obras: }\end{array}$ \\
\hline $1^{\mathrm{a}}$ & Data de Publicação & 6 \\
$2^{\mathrm{a}}$ & Duplicidade de Abordagem & 8 \\
\hline \multicolumn{2}{|c|}{ Total de Obras Excluídas: } & $\mathbf{1 4}$ \\
\hline
\end{tabular}

Fonte: Própria Autora (2019).

\section{PROTOCOLO DA REVISÃO NARRATIVA DE LITERATURA}

O Protocolo da Revisão Narrativa foi realizado em "6" etapas: iniciando no processo de seleção e eliminação de obras, passando pela construção/desenvolvimento do conteúdo até a conclusão final da pesquisa. 
A primeira etapa do Protocolo foi de listagem das obras científicas que compõem o conteúdo bibliográfico, identificando-as por assunto/enfoque, em relação ao total de "26" (100\%), pertinente aos descritores, temática e abordagem. A "Tabela 3" apresenta a distribuição do conteúdo por assunto/enfoque e a porcentagem desses no total de "26" conteúdos, conforme a sua relação com os descritores da pesquisa, independentemente das categorias desses conteúdos.

Tabela 3: Distribuição das Obras que compõem o Conteúdo, por Assunto.

\begin{tabular}{|l|c|c|}
\hline \multicolumn{1}{|c|}{ Relação de Obras por Assunto/Enfoque: } & N de Obras: $^{\mathbf{0}}$ \% em relação à '36' Obras: \\
\hline Teoria Rogeriana & 1 & 3,84 \\
Processo de Gestão do Conhecimento & 4 & 15,38 \\
Interação entre Processo Comportamental e Gestão do Saber & 2 & 7,69 \\
Atividades de Ensino-aprendizagem & 3 & 11,53 \\
Métodos Ativos & 2 & 7,69 \\
Limites e Possibilidades de Tutorização do Conhecimento & 1 & 3,84 \\
Apropriação do Conhecimento em Escolas Públicas & 6 & 23,07 \\
Aprendizagem Baseada em Problemas (ABP) & 2 & 7,69 \\
O Professor como facilitador do Aprendizado & 8 & 30,76 \\
História e Políticas da Educação & 1 & 3,84 \\
\hline
\end{tabular}

Fonte: Própria Autora (2019).

*O número de conteúdos selecionados por assunto é superior ao número total de obras referenciadas, levando-se em consideração de que um mesmo conteúdo pode abordar mais de um assunto.

A segunda etapa foi de construção dos resumos das obras, seguida da leitura dessas publicações para a criação de "fichas bibliográficas" previamente elaboradas com os seguintes tópicos: autor; título; tipo de publicação; local da publicação, mês e ano; categoria dos conteúdos e dos autores; número de autores; sujeitos da pesquisa; resumo e objetivo de cada obra.

A terceira etapa foi de extração de informações para criação dos tópicos (títulos), conforme a técnica metodológica aplicada no desenvolvimento do estudo e, sem seguida, foi realizada a quarta etapa, que foi de análise dos dados e apresentação dos resultados, de maneira narrativa.

A quinta etapa foi o momento de discussão dos dados com os autores referenciados, seguida da sexta e última etapa do Protocolo de Revisão Narrativa onde ocorreu a construção e apresentação da conclusão.

\section{ANÁLISE E RESULTADOS}

$\mathrm{Na}$ base de dados BVE, plataformas da web, e editoriais, no período de 1992 a 2019 foram identificadas " 26 " obras científicas que cumpriam os critérios de inclusão e foram selecionadas. No total de "26" conteúdos aplicou-se um processo de eliminação por filtros, restando "12" obras para compor a relação de referências bibliográficas, onde os artigos de 
revistas e informativos de portais $(n=9)$ foram as publicações que mais se destacaram, sendo "8" artigos nacionais e " 1 " internacional (de revista portuguesa), e os demais conteúdos (n=3) são materiais didático-científicos de editoras nacionais.

No que diz respeito à qualificação dos autores, identificamos que os docentes estão entre os que mais publicaram $(n=12)$. Outro dado pesquisado foi em relação ao número de autores, sendo possível perceber que o interesse em desenvolverem trabalhos em grupos $(n=6)$ se equiparou ao número de publicações desenvolvidas por um único autor $(n=6)$.

Em relação às categorias dos conteúdos, tem-se que os de pesquisa científica educacional $(\mathrm{n}=12)$ predominaram, sendo que " 5 " foram obras quali-quantitativas, "4" bibliográficas exploratórias, "1" revisão narrativa de literatura, e "2" bibliográficas explicativas.

Dentre todos os conteúdos (pesquisas bibliográficas, de reflexão e estudo teórico) pesquisados encontramos outro dado importante em relação à Apropriação e Gestão do Conhecimento, onde a maioria $(n=8)$ dos autores acredita que esse processo só ocorre quando o fator preponderante é o "trabalho", mas os demais $(\mathrm{n}=4)$ afirmaram que o saber também se constitui como um diferencial de valor pessoal dos sujeitos no cotidiano.

Percebe-se que a maior preocupação dos pesquisadores está nos resultados da aplicação dos métodos de ensino, além da importância da cumplicidade entre os atores envolvidos no cenário escolar $(n=12)$, onde uma boa parte dos conteúdos $(n=9)$ sugeriu propostas de mudança e reestruturação do ensino profissional e politécnico, que podem vir a comprometer a formação humana, por seus pressupostos e apropriações ideológicas não questionadas.

Os riscos que a "não apropriação" do conhecimento pode oferecer à sociedade em geral foram citados em "3" dentre os "12" conteúdos referenciados, sendo que eles se relacionaram ao desenvolvimento do trabalho no mundo capitalista da atualidade.

Quanto às condições de trabalho dos profissionais da educação e/ou necessidade de capacitação foi o assunto menos abordado $(n=1)$, porque se entende que todo Pedagogo possui qualidades e valores para o exercício de educador no contexto social de hoje.

Foi citada em " 2 " dos conteúdos a necessidade de ética no uso das ferramentas da Tecnologia da Informação e Comunicação em sala de aula, que não devem influenciar no diálogo e cumplicidade entre professor e aluno que precisam ser mantidos no processo de transmissão do conhecimento.

Em relação às propostas sugeridas pelos autores, nelas esteve presente o método de Aprendizagem Baseada em Problemas (ABP), ideal para a transformação dos alunos em 
sujeitos sociais. Entretanto, houve unanimidade entre os autores em relação à necessidade de apropriação e gestão do conhecimento como fator fundamental no processo de ensinoaprendizagem, para que os alunos se tornem cidadãos contributivos na sociedade em que se encontram inseridos.

A literatura foi enfática em apontar que a subjetividade dos autores referenciados que, em sua totalidade, se constitui por profissionais da educação brasileira, deve ser respeitada, contraindicando padronizações ou uma generalização de condutas "não metodológicas", como aquela que se costuma identificar nas escolas públicas do Brasil, apesar da literatura nacional apresentar relevante produção sobre o tema. No entanto, novos estudos direcionados ao planejamento e produção de metodologias inovadoras formam recomendados, acrescentando que devem ser aplicáveis à realidade educacional brasileira.

\section{DISCUSSÃO}

Considerando ser uma revisão narrativa da literatura, esta pesquisa limitou-se em destacar a importância da escolha adequada do método de ensino no processo de ensinoaprendizagem para que se obtenha o resultado desejado: a transformação do aluno em tutor do próprio conhecimento por ele apropriado em sala de aula.

A discussão dos dados, para um melhor entendimento do leitor, será apresentada de acordo a relação de referências bibliográficas deste estudo, isto é, na mesma ordem. As abordagens e concepções dos autores serão analisadas e debatidas separadamente, respeitando a sua subjetividade, independente da natureza e/ou caracterização do assunto.

O editorial de Camillo e Medeiros (2018) se resume em um estudo reflexivo sobre os "marcos" históricos da educação brasileira, com o intuito de estimular a compreensão sobre as teorias expostas, relacionando-as com os aspectos vivenciados no cenário escolar, os quais também se encontram presentes no cotidiano do aluno, onde ele precisa ser capaz de refletir o aprendizado. As autoras concluíram que a educação nova veio transformar não só o campo educacional como também a sociedade, possibilitando a exposição do conhecimento em diversos níveis de relações entre a educação, a sociedade e a política (CAMILLO; MEDEIROS, 2018, p. 27). As escolas se transformaram em instituições estimuladoras do desenvolvimento e dos ideais formativos, se contrapondo ao modelo de pedagogia tradicional, de educação conteudista, enquanto a escola nova procura preparar os sujeitos, desde cedo, a partir de processos de socialização, dentro de uma proposta democrática, para a sua inclusão na vida em sociedade. O "Quadro 1" apresenta a nova roupagem que as escolas vêm 
promovendo na redefinição da pedagogia, segundo as autoras, tornando os processos mais articulados, com a finalidade de formar cidadãos críticos e conscientes.

Quadro 1: Principais Ideias das Escolas Tradicional e Nova.

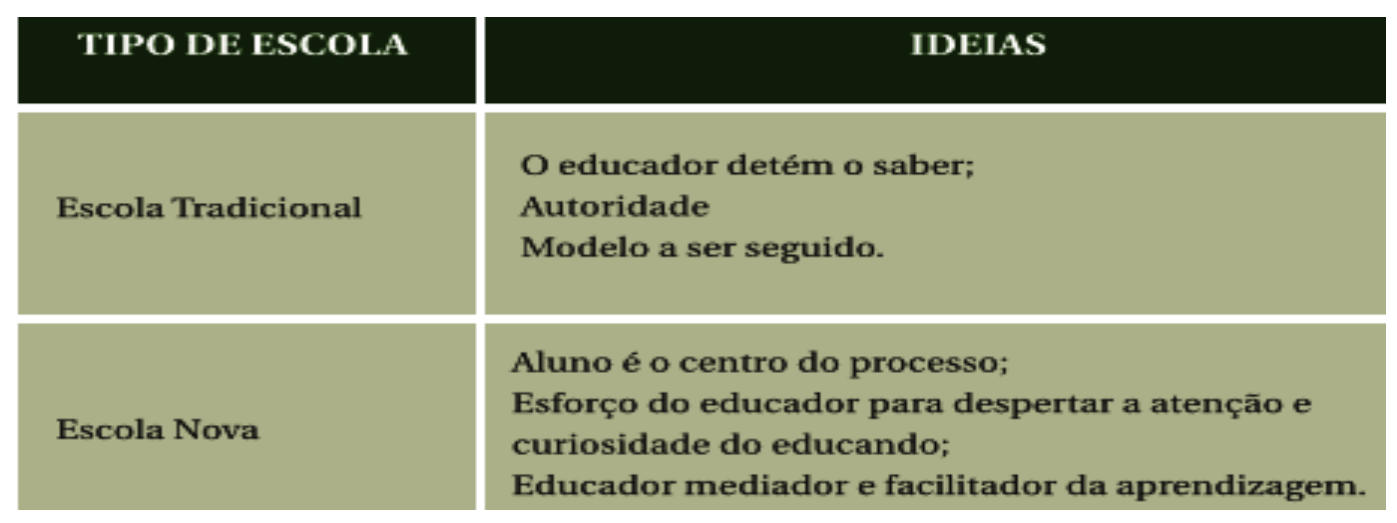

Fonte: CAMILLO, MEDEIROS (2018, p. 27).

Davila et al (2015) investigaram sobre a prática do ciclo de gestão do conhecimento, com base em um estudo em dois núcleos empresariais de Santa Catarina, com o objetivo de analisar o desenvolvimento desse processo no ambiente organizacional, lugar onde deve ser realizada a conversão do conhecimento em "valor". Constatou-se nestas empresas que o conhecimento é um "ativo" fundamental na competitividade do mercado atual, o qual se constitui em uma contribuição empírica "indevidamente" explorada, mas que precisa ser identificada e gerenciada, adequadamente. Segundo os autores, há o conhecimento tácito e o explícito, sendo que é a interação que forma a "espiral" do conhecimento organizacional ocorre em quatro etapas de conversão (DAVILA; et al, 2015, p. 46-47), que são:

1) Socialização: representando o compartilhamento do conhecimento tácito entre os indivíduos;

2) Externalização: que é a explicitação do conhecimento tácito individual para o grupo;

3) Combinação: que é a difusão e sistematização do conhecimento gerado na etapa de externalização; e

4) Internalização: sendo a conversão do conhecimento recém-criado em conhecimento tácito da organização.

Prosseguem Davila et al (2015), acrescentando que:

O conhecimento tácito é definido como conhecimento subjetivo sendo resultado de experiências e estudo, apresentando natureza procedural e resultando numa difícil verbalização, reprodução ou armazenamento em documentos e bases de conhecimento. Já o conhecimento explícito é objetivo, pode ser codificado, sistematizado e compartilhado, é de natureza declarativa e está formalizado em manuais, relatos, pesquisas, relatórios e afins através de uma linguagem formal e sistemática [...] (DAVILA; et al, 2015, p. 46-47). 
O "Quadro 2" vem ilustrar os modos de conversão do conhecimento, de acordo com os autores Davila et al (2015).

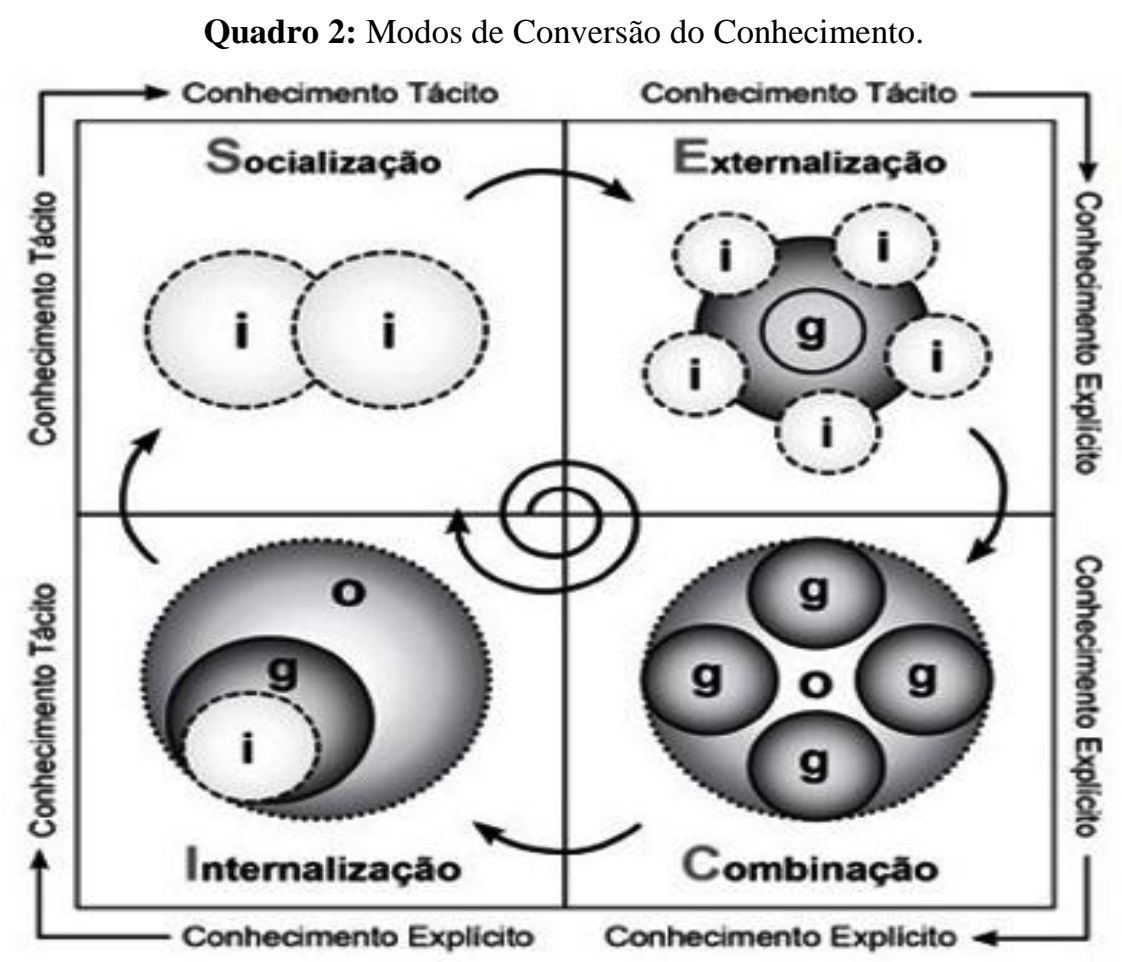

\section{(i) individuo (9) grupo (0) organização}

Fonte: Nonaka e Takeuchi (1995 apud DAVILA; et al, 2015, p. 47).

Ferrari (2008) apresentou um estudo sobre a terapia não-diretiva de Carl Rogers, que traduz a tarefa do educador em liberar o caminho para que o aluno aprenda o que desejar, se opondo às concepções e práticas dominantes, pois a teoria rogeriana é centrada no pacientealuno. Segundo Ferrari, se o professor é o terapeuta e o aluno é o paciente, a tarefa é facilitar o processo de aprendizado, onde o aluno é quem o conduzirá a seu modo, portanto: “[...] do conflito entre o indivíduo ("sou") e o que se exige dele ("devo ser") nasce o que Rogers chama de incongruência, que gera sofrimento. Esse é o processo que, para ele, define neurose" (FERRARI, 2008, p. 2).

Gonzalez e Martins (2017) realizaram um estudo teórico-conceitual a respeito do processo de Gestão do Conhecimento (GC), onde apontaram que ele é constituído por quatro etapas: “[...] aquisição, armazenamento, distribuição e utilização do conhecimento" (p. 1). Afirmaram os autores, que a evolução do conceito da teria de ensino-aprendizagem parte da visão de que a lucratividade é explicitada em função dos fatores produtivos, que são dependentes da apropriação e gestão do conhecimento nas organizações, segundo as quais as empresas geram valor e competitividade no mercado. Mas, a vantagem competitiva só é alcançada através do aprendizado contínuo e da inovação simultânea do processo produtivo e 
do produto, onde o conhecimento é o principal recurso da organização. O "Quadro 3" mostra as etapas do processo de Apropriação e GC, segundo os autores.

Quadro 3: Etapas dos Processos de Apropriação e Gestão do Conhecimento.

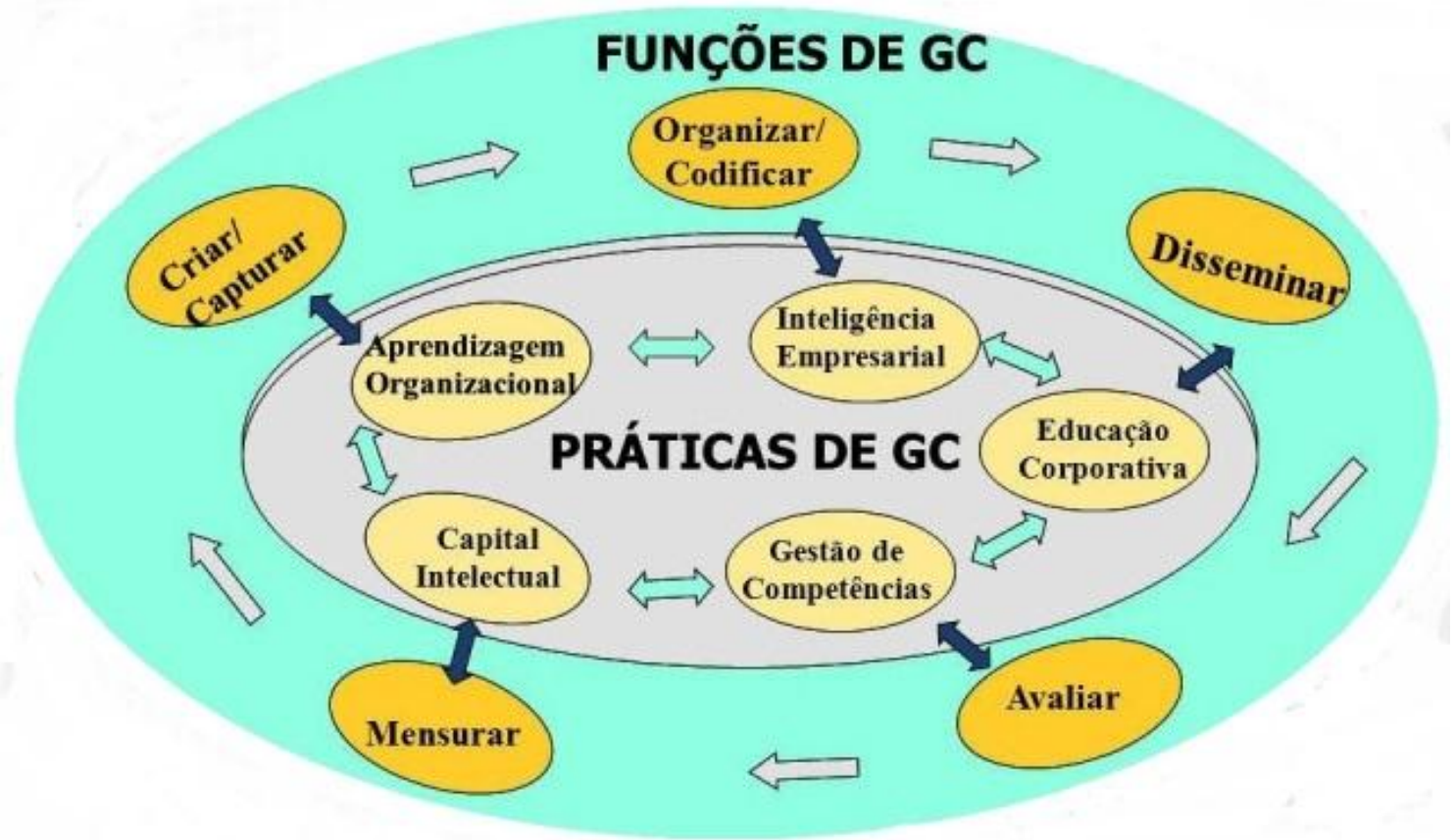

Fonte: Adaptado de GONZALEZ; MARTINS (2017, p. 250).

Kubo e Botomé (2005) pesquisaram o processo de ensino-aprendizagem como sistema de interações comportamentais entre professores e alunos, concluindo que se trata de dois processos independentes da ação humana (os fenômenos "ensinar" e "aprender"), sendo que ambos constituídos por comportamentos complexos e de difícil percepção, apesar de serem interdependentes. Essa relação funcional formada por diferentes comportamentos está sendo apresentada nos “Quadros 4, 5 e 6”, segundo conclusão dos autores, após a investigação.

Quadro 4: Explicitação esquemática de componentes do processo de ensino-aprendizagem.

\begin{tabular}{|c|c|c|}
\hline \multicolumn{3}{|c|}{ COMPORTAMENTO DE ENSINAR } \\
\hline SITUAÇĀO ANTECEDENTE & $\begin{array}{l}\text { CLASSE DE } \\
\text { RESPOSTAS DO } \\
\text { PROFESSOR }\end{array}$ & $\begin{array}{c}\text { SITUAČĀO } \\
\text { CONSEQŨENTE }\end{array}$ \\
\hline $\begin{array}{l}\text { - Objetivos de ensino definidos } \\
\text { (descriçăo do desempenho final } \\
\text { do aprendiz ou de outras } \\
\text { concepçס̄es de objetivos, do } \\
\text { professor) } \\
\text { - características dos aprendizes: } \\
\text { - capacidade de desempenho } \\
\text { inicial dos aprendizes; } \\
\text { - interesses; } \\
\text { - etc. }\end{array}$ & $\begin{array}{l}\text { Quaisquer classes de } \\
\text { respostas do professor }\end{array}$ & $\begin{array}{l}\text { - Desempenho do } \\
\text { aprendiz, de } \\
\text { acordo com } \\
\text { objetivos } \\
\text { definidos pelo } \\
\text { professor } \\
\text { - Outros } \\
\text { desempenhos do } \\
\text { aprendiz }\end{array}$ \\
\hline - matérias e condiçōes de ensino & & \\
\hline
\end{tabular}

Fonte: KUBO; BOTOMÉ (2005, p.6). 
Quadro 5: Componentes do comportamento de quem "não prendeu" que permitem a identificação do tipo de relação entre o sujeito e o lugar (escola), resultado do método de ensino implementado pelo educador.

\begin{tabular}{|c|c|c|}
\hline \multicolumn{3}{|c|}{ COMPORTAMENTO DE QUEM "NĀO APRENDEU" } \\
\hline $\begin{array}{l}\text { Caracteristicas } \\
\text { da situação } \\
\text { antecedente }\end{array}$ & $\begin{array}{l}\text { Características das } \\
\text { classes de respostas } \\
\text { do organismo }\end{array}$ & $\begin{array}{c}\text { Caracteristicas dos } \\
\text { produtos ou resultados das } \\
\text { classes de respostas do } \\
\text { organismo }\end{array}$ \\
\hline $\begin{array}{l}\text { - situação-problema para } \\
\text { o organismo ou para a } \\
\text { sociedade com que o } \\
\text { organismo se relaciona } \\
\text { - caracteristicas gerais } \\
\text { do organismo: físicas, } \\
\text { repertorio, interesses... } \\
\text { - recursos disponiveis } \\
\text { para o organismo lidar } \\
\text { com a situaçăo- } \\
\text { problema } \\
\text { - prejuizos ou sofrimento } \\
\text { resultantes da situaçăo- } \\
\text { problema e do } \\
\text { desempenho do } \\
\text { organismo diante da } \\
\text { situaçăo-problema } \\
\\
\text { - (...) }\end{array}$ & $\begin{array}{l}\text { - apresentar açóes que } \\
\text { conhece ou com as } \\
\text { quais está acostumado } \\
\text { - testar "soluçóes" } \\
\text { diversas (ensaio e } \\
\text { erro), sem critérios ou } \\
\text { com critérios } \\
\text { inadequados } \\
\text { - variar as açóes de } \\
\text { acordo com critérios } \\
\text { irrelevantes ou } \\
\text { inadequados } \\
\text { - repetir uma mesma } \\
\text { açăo, múltiplas vezes } \\
\text { - variar as dimensóes } \\
\text { (força, forma, laténcia, } \\
\text { freqūência etc.) de uma } \\
\text { mesma classe de } \\
\text { respostas } \\
\text { - (...) }\end{array}$ & $\begin{array}{l}\text { - a situaçăo-problema } \\
\text { permanece inalterada ou } \\
\text { insuficientemente alterada } \\
\text { para o individuo ou para a } \\
\text { sociedade com que o } \\
\text { organismo se relaciona } \\
\text { - alteraçбes nas } \\
\text { caracteristicas do } \\
\text { organismo: desgaste físico, } \\
\text { cansaço, desânimo, } \\
\text { diminuiçăo de auto- } \\
\text { confiança... } \\
\text { - alto custo para obter algum } \\
\text { grau de soluçăo para a } \\
\text { situaçăo-problema: muito } \\
\text { tempo, muito desgaste, } \\
\text { pouco acúmulo de "expe- } \\
\text { riência"... } \\
\end{array}$ \\
\hline
\end{tabular}

Fonte: KUBO; BOTOMÉ (2005, p. 7).

Quadro 6: Componentes do comportamento de quem se apropriou do conhecimento e se transformou em "tutor" do seu próprio saber.

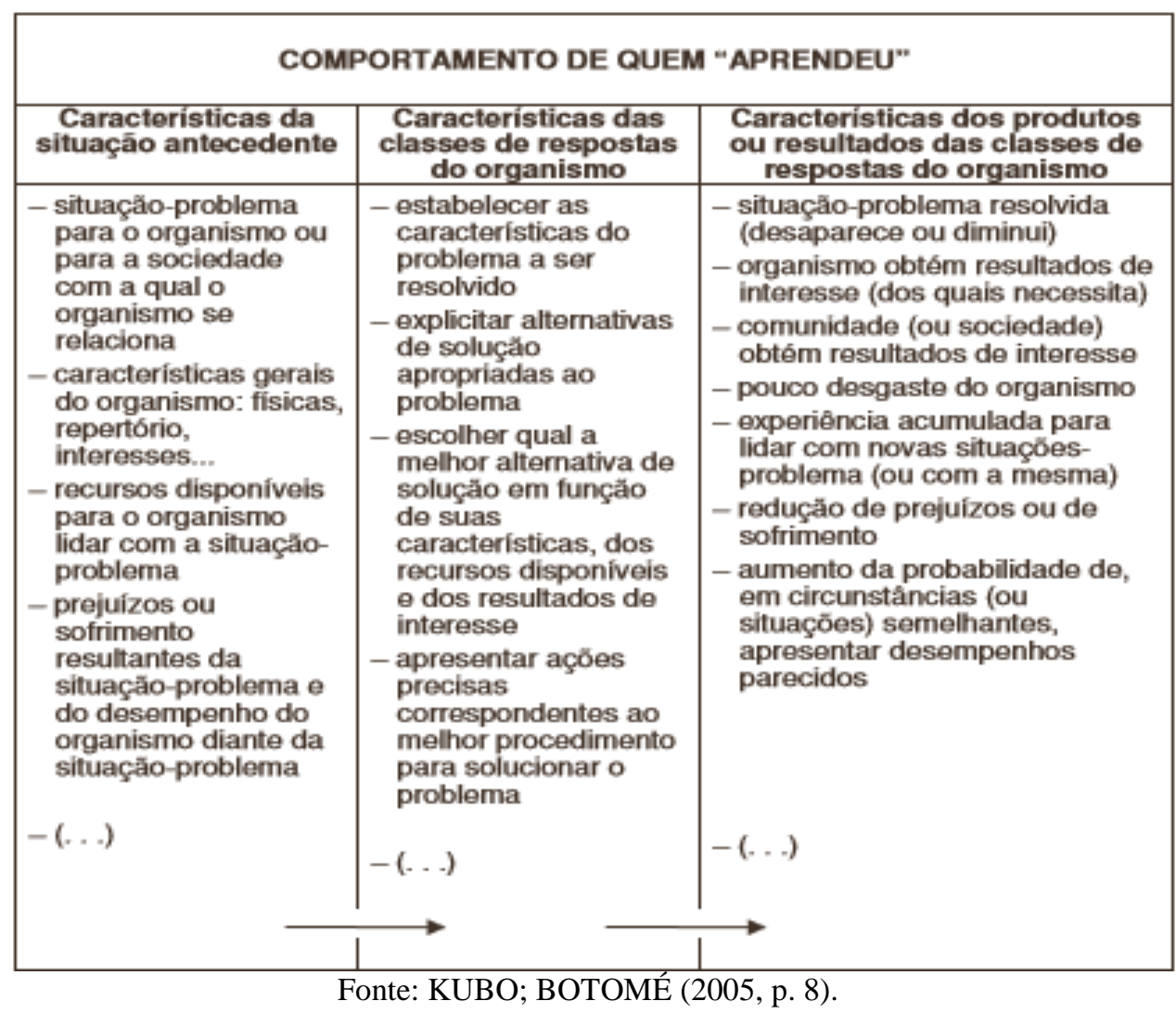


O editorial de Ramos (2014) tratou dos conceitos concretos e métodos ativos de ensino-aprendizagem, apresentando as observações pessoais da autora sobre essas práticas, que confrontam a política nacional. A autora pôde concluir que a política educacional brasileira da atualidade foi fundamentada para fortalecer a produção do capital, que se encontra comprometida pela falta de capacidade e qualificação profissional dos cidadãos. Entretanto, cabe à sociedade lutar pelo direito em formar cidadãos sociais e contributivos.

Russo e Taglieber (1992) apresentaram um estudo conceitual e reflexivo sobre os métodos ativos de ensino e a prática de suas atividades, visando promover uma reflexão sobre a ação docente em sala de aula que, conforme a opinião dos autores, ela se encontra sob: “[...] sob a ótica de critérios piagetianos dos métodos ativos e atividade” (p. 37). Nessa pesquisa, considerou-se a importância da obra de Piaget (1980) no seu livro "Psicologia e Pedagogia", onde foram analisados os novos métodos de aprendizagem e seus indicativos, em presença da metodologia tradicional, comparando o grau de autonomia e atividade do aluno, como se pode observar no "Quadro 7". Na conclusão, os autores fizeram das palavras de Piaget as suas, afirmando que "o conhecimento é formado por construções gradativas do indivíduo, conforme a evolução intelectual”.

Quadro 7: Exposição do caráter metodológico e pragmático dos Métodos Ativos de Ensino-aprendizagem.

\begin{tabular}{|c|c|}
\hline $\begin{array}{c}\text { AUXILIOS } \\
\text { (fatores que podem estimular o } \\
\text { pensamento) }\end{array}$ & \multicolumn{1}{c|}{$\begin{array}{c}\text { OBSTÁCULOS } \\
\text { (fatores podem dificultar o } \\
\text { pensamento) }\end{array}$} \\
$\begin{array}{l}\text { 1. O aluno realiza a atividade. } \\
\text { 2. O professor aceita o aluno e seus } \\
\text { esforços de realizaçấ. }\end{array}$ & $\begin{array}{l}\text { O professor realiza a atividade. } \\
\text { O professor rejeita o aluno e seus } \\
\text { esforços. }\end{array}$ \\
$\begin{array}{l}\text { 3. As atividades têm um objetivo ou } \\
\text { um significado. }\end{array}$ & $\begin{array}{l}\text { As atividades são quase sempre } \\
\text { insignificantes. }\end{array}$ \\
\hline
\end{tabular}

Fonte: RUSSO; TAGLIEBER (1992, p. 7).

Santos e Paula (2012) fundamentaram a gestão do conhecimento no contexto escolar, a partir de um estudo de caso em uma escola pública de Minas Gerais, onde concluíram que, tanto a apropriação como a gestão do conhecimento, dependem do método de ensino que é posto em prática como ferramenta da gestão escolar, além do ambiente em sala de aula.

Scremin e Mendes (2008) investigaram sobre as possibilidade e limitações da gestão do conhecimento, a partir da sala de aula, afirmando que a escola se constitui no "lugar" apropriado para que a proposição de sentidos e significados na reprodução de reflexões e entraves extraídos do cotidiano possam trazer bons resultados, em presença dos protagonistas de direito e de fato: professor e aluno. 
Souza e Dourado (2015) apontaram a Aprendizagem Baseada em Problemas (ABP) como um método inovador no ensino educativo, que oferece resultados positivos em diferentes áreas e níveis (fundamental, médio e superior). Nesse cenário, os estudantes trabalham para solucionar um problema real ou simulado, extraído do cotidiano do educando. A principal vantagem do método é a motivação ativada pelo dinamismo do grupo.

O editorial científico produzido pela Universidade Federal do Rio Grande buscou esclarecer os questionamentos que envolvem a modalidade de Ensino à Distância (EAD) como a prática de ensino individual que mais cresce no Brasil, onde o "tutor" atua, simultaneamente, como mediador, facilitador e investigador do conhecimento e da prática de aprendizagem, concluindo que a ausência da cumplicidade do educador pode gerar graves consequências para o educando e sociedade.

Tavares (2019) investigou o papel do educador como facilitador do aprendizado, mediante a necessidade do emprego de um método ativo transformador, com o intuito de responder aos questionamentos de alguns professores que acreditam desperdiçar seu conhecimento praticando essas habilidades. A autora concluiu o seu artigo afirmando que: “[...] o conhecimento, a experiência e as habilidades do professor não são apenas importantes para que as metodologias ativas de ensino tenham êxito em melhorar o aprendizado. Eles são fundamentais!" (TAVARES, 2019, p. 2).

\section{CONCLUSÃO}

Esta revisão narrativa veio contribuir para uma melhor compreensão de que a escola é o lugar onde o processo de apropriação do conhecimento é realizado, onde são identificadas as principais repercussões relacionadas ao aluno, para que se torne o tutor do "saber" adquirido em sala de aula, o que vai depender da funcionalidade do método de ensinoaprendizagem aplicado pelo educador.

Procurou-se, de forma clara e objetiva, identificar e especificar a metodologia de ensino como um instrumento de transformação do sujeito no processo de apropriação do saber adquirido, tendo como base o conteúdo bibliográfico referenciado, além de responder à questão norteadora, e contribuir com melhores práticas profissionais relacionadas ao tema.

A avaliação das informações levou a Autora-Pesquisadora a identificar o método da Aprendizagem Baseada em Problemas (ABP) como o mais adequado em comparação com outras metodologias ativas, para que se tenha sucesso nos resultados da cumplicidade e conspiração entre os atores protagonistas da educação (professor e aluno). Portanto, a ABP se constitui em um instrumento facilitar da apropriação e gestão do conhecimento pelo aluno. 
Os resultados da revisão narrativa nos mostraram que a educação das escolas públicas precisa ser reestruturada, de forma que proporcione aos estudantes a oportunidade de contribuir com o enriquecimento cultural e humano da nossa população, porque a prática da tutorização do conhecimento, além de ser um fator essencial à vida do cidadão, proporciona o crescimento socioeconômico do país.

Todos os resultados encontrados têm em comum o fortalecimento de ações que se articulam: "[...] ao saber específico e prático, que se desenvolve no interior do processo produtivo, e mediante a dotação de traços ideológicos, necessários ao capital, para a grande massa de trabalhadores que constituem o corpo coletivo de trabalho" (FRIGOTTO ${ }^{2}, 2010$, p. 249).

Houve unanimidade entre os autores de que a escola é o "lugar" de apropriação do conhecimento e que a prática do educador deve seguir um "método ativo" e eficaz de ensinoaprendizagem, de modo que venha formar cidadãos tutores do conhecimento adquirido na escola, com o qual contribuirão para o desenvolvimento econômico e social do país.

A presente pesquisa pôde privilegiar os estudantes e educadores com informações precisas para a tomada de decisão na implementação de metodologias inovadoras nas escolas brasileiras, seja nos aspectos sociais ou políticos, em relação ao papel do professor como figura indispensável de mudança e desenvolvimento da sociedade.

\section{REFERÊNCIAS BIBLIOGRÁFICAS}

CAMILlO, Cíntia Moralles; MEDEIROS, Camillo Liziany Müller. Teorias da Educação. Santa Maria: NTE, 2018.

DAVILA, Guillermo Antonio; et al. O ciclo de Gestão do Conhecimento na prática: um estudo nos núcleos empresariais catarinenses. Revista Inst. J. Knowl Eng. Manage. Santa Catarina: v. 3, n. 7, p. 43-64, nov. 2014/fev. 2015. Disponível em: 〈http://www.scielo.br/pdf/gp/v24n2/0104-530X-gp-0104-530X0893-15.pdf>. Acesso em: 10 jul. 2019.

FERRARI, Márcio. Carl Rogers, um psicólogo a serviço do estudante. Portal Nova Escola. Brasília: 01 out. 2008. Disponível em: <https://novaescola.org.br/conteudo/1453/carl-rogersum-psicologo-a-servico-do-estudante>. Acesso em: 10 jul. 2019.

GONZALEZ, Rodrigo Valio Dominguez; MARTINS, Manoel Fernando. O Processo de Gestão do Conhecimento: uma pesquisa teórico-conceitual. Revista Gestão da Produção. São Carlos: v. 24, n. 2, p. 248-265, 2017. Disponível em: < http://www.scielo.br/pdf/gp/v24n2/0104-530X-gp-0104-530X0893-15.pdf >. Acesso em: 04 jul. 2019.

\footnotetext{
${ }^{2}$ FRIGOTTO, Gaudêncio. A Produtividade da Escola Improdutiva. 9a ed. São Paulo: Cortez, 2010, 263p.
} 
KUBO, Olga Mitsue; BOTOMÉ, Sílvio Paulo. Ensino-Aprendizagem: uma interação entre dois processos comportamentais. Revista da UFSC. Santa Catarina: dez. 2005. Disponível em: $\quad$ https://www.researchgate.net/publication/273025200_Ensinoaprendizagem_uma_interacao_entre_dois_processos_comportamentais $>$. Acesso em: 15 jul. 2019.

RAMOS, Marise Nogueira. História e Política da Educação Profissional. $1^{\text {a }}$ ed. Coleção Formação Pedagógica. Curitiba: IFPR, 2014.

ROSSO, Ademir José; TAGLIEBER, José Erno. Métodos Ativos e Atividade de Ensino. Revista Perspectiva. Santa Catarina: n. 17, p. 37-46, 1992. Disponível em: < https://periodicos.ufsc.br/index.php/perspectiva/article/download/9147/10689>. Acesso em: 20 jul. 2019.

SANTOS, Márcio José dos; PAULA, Cláudio Paixão Anastácio de. Gestão do Conhecimento no contexto da Gestão Escolar: Estudo de Caso de uma escola pública. Revista Perspectiva em Gestão \& Conhecimento. João Pessoa: v. 2, n. esp., p. 159-174, out. 2012. Disponível em: 〈http://periodicos.ufpb.br/ojs2/index.php/pgc >. Acesso em: 10 jul. 2019.

SCREMIN, Tânia Mara Trentin; MENDES, Marjorie Bitencourt Emilio. Gestão do Conhecimento na sala de aula: limites e possibilidades. Portal Dia-a-dia Educação. Paraná: 06 dez. 2008. Disponível em: 〈http://www.diaadiaeducacao.pr.gov.br/portals/pde/arquivos/2023-8.pdf >. Acesso em: 19 jul. 2019.

SOUZA, S. C.; DOURADO, L. Aprendizagem Baseada em Problema (ABP): um método de aprendizagem inovador para o ensino educativo. Revista Holos. Portugal: v. 5, n. 31, set. 2015. Disponível em: http://www2.ifrn.edu.br/ojs/index.php/HOLOS/article/download/2880/1143>. Acesso em; 20 jul. 2019.

TAVARES, Priscilla de Albuquerque. Metodologias ativas: o papel do professor como facilitador do aprendizado dos alunos. Portal Nova Escola. Brasília: 24 jan. 2019. Disponível em: <https://novaescola.org.br/conteudo/15340/metodologias-ativas-o-papel-doprofessor-como-facilitador-do-aprendizado-dos-alunos>. Acesso em: 10 jul. 2019.

UNIVERSIDADE FEDERALDO DO RIO GRANDE - UFRG. Tutor/Autor. Experiências e Saberes. Rio Grande: FURG, 2013. 